Review

\title{
Cryoablation versus Partial Nephrectomy for Clinical Stage T1 Renal Masses: A Systematic Review and Meta-Analysis
}

\author{
Wen Deng1 ${ }^{*}$, Luyao Chen ${ }^{*}$, Yibing Wang2 ${ }^{2}$ Xiaoqiang Liu ${ }^{1}$, Gongxian Wang1, Weipeng Liu ${ }^{1}$, Cheng Zhang1, \\ Xiaochen $\mathrm{Zhou}^{1}, \mathrm{Yu} \mathrm{Li}^{1}$, Bin Fu${ }^{1 凶}$ \\ 1. Department of Urology, the First Affiliated Hospital of Nanchang University, Nanchang City, Jiangxi Province, China. \\ 2. Department of Emergency, the Second Affiliated Hospital of Nanchang University, Nanchang City, Jiangxi Province, China. \\ * Wen Deng and Luyao Chen contributed equally to this work. \\ $\square$ Corresponding author: Bin Fu. Phone number: 8618720919501; Fax number: +86-079188698102; E-mail: urofbin@email.ncu.edu.cn. \\ (c) Ivyspring International Publisher. This is an open access article distributed under the terms of the Creative Commons Attribution (CC BY-NC) license \\ (https://creativecommons.org/licenses/by-nc/4.0/). See http://ivyspring.com/terms for full terms and conditions.
}

Received: 2018.07.31; Accepted: 2018.12.20; Published: 2019.01.29

\begin{abstract}
Introduction: Cryoablation has been considered as the most efficacious ablative alternative to partial nephrectomy (PN) for selected patients. Our objective is to assess the existing evidence relating to the safety and efficacy of cryoablation compared with PN for clinical TI renal masses.

Materials and Methods: A comprehensive search of PMC, EMBASE, and the Cochrane Library was conducted to identify studies containing comparison of cryoablation and PN. By utilizing those included studies, a systematic review and cumulative meta-analyses were performed to assess the safety and efficacy between cryoablation and PN for T1 renal masses.

Results: 17 retrospective studies providing available data were included in our study. Significant differences were found about all oncological variables including all-cause death, cancer-specific death, metastasis and local-recurrence $(p<0.001, p=0.03, p<0.001$, and $p<0.001$, respectively) between the $\mathrm{PN}$ group and the cryoablation group. The mean difference between two groups for percent estimated glomerular filtration rate decrease and creatinine increase was -4.84 and 0.15 respectively $(p<0.001$ and $\mathrm{P}=0.006$, respectively). The incidences of overall and postoperative complications in the $\mathrm{PN}$ group were significantly higher than that in the cryoablation group ( $p=0.001$ and $p<0.001$, respectively), but the result about intraoperative complications didn't show a significant difference between the two groups ( $\mathrm{P}$ $=0.53$ ).

Conclusions: Comparing with PN, cryoablation for clinical Tl renal tumors is associated with poorer oncological outcomes, but the existing disadvantages are accompanied by lower rate of overall and postoperative complications and superior renal functional preservation. For patients with imperative indications for nephron-sparing surgery who can't risk more invasive PN, cryoablation could be an attractive option. Owing to the inherent limitations of eligible studies, conclusions drawn from our meta-analyses should be interpreted cautiously and be confirmed further with well-designed randomized controlled trials with extensive follow-up length.
\end{abstract}

Key words: cryoablation; partial nephrectomy; renal mass; clinical T1; meta-analysis

\section{Introduction}

An increase in newly detection of incidental small renal masses has reached to $2 \%-3.1 \%$ per year owing to routine application of multiple imaging modalities [1, 2]. Small renal tumors were more likely to originate in patients with elderly age and comorbidities [3]. That's why sufficient renal function preservation and fewer complications were also important besides satisfactory oncological outcomes.

Partial nephrectomy (PN) has been adopted as standard treatment for stage T1a renal tumors. 
Recently guideline has recommended PN rather than radical nephrectomy as management for selected $\mathrm{T} 1 \mathrm{~b}$ renal tumors [4]. PN can be conducted under open conditions, with laparoscopy or robotic assistance [5, 6].

Ablative therapies have been regarded as an alternative method to $\mathrm{PN}[7,8]$. Most frequent ablative technologies are cryoablation and radiofrequency ablation [9]. Cryoablation was considered as the most efficacious alternative to PN because of the lower possibility of local-recurrence and metastatic progression compared with radiofrequency ablation $[9,10]$. Cryoablation can be performed with laparoscopy or percutaneous image guidance. Both approaches were reported to be safe and efficient to treat stage T1 renal tumors [11, 12].

More and more articles have reported that cryoablation could be applied for renal tumors up to $\mathrm{T} 1 \mathrm{~b}$ but not limited to small renal masses (usually defined as renal mass $\leq 4 \mathrm{~cm}$ ) [8, 13, 14]. A meta-analysis comparing laparoscopic cryoablation with laparoscopic PN for small renal masses has been reported [15]. However, no study systematically reviewed cryoablation for T1 renal tumors compared with PN. Several studies have compared cryoablation and PN applied to T1 renal masses [2, 3, 8, 10, 13, 14, 16-26], which may provide evidence that cryoablation could be an alternative challenging PN for surgical high-risk patients with T1 renal masses. Along with those series, a systematic review and meta-analysis was carried out to investigate the efficacy and safety of cryoablation for T1 renal masses compared with PN.

\section{Materials and Methods}

\section{Data Sources and Searches}

A comprehensive literature search utilizing the major electronic databases (PMC, EMBASE and the Cochrane Library) up to September 2018 was not restricted to regions or languages. ("partial nephrectomy" [Title/Abstract] or "nephron sparing surgery" [Title/Abstract]) and ("cryoablation" [Title/Abstract] or "cryotherapy" [Title/Abstract]) were combined as search terms. Related articles were also identified manually with screening the reference lists of all retrieved articles.

\section{Inclusion and Exclusion Criteria}

The following inclusion criteria were necessary: (1) Article has been published or accepted for full-length publication; (2) Article must be designed as a prospective or retrospective study that compared cryoablation and PN for T1 renal tumors; (3) At least one of the outcomes of interest below is evaluated and data is extractable.
The following exclusion criteria were used: (1) A review or meta-analysis; (2) No available data could be extracted. (3) Editorials, letters, case report or animal experimental studies.

\section{Outcome of Interest and Definitions}

Following outcome variables were extracted to assess the efficiency and safety between cryoablation and $\mathrm{PN}$.

1. Oncological variables: all-cause death, cancer-specific death, metastasis, local-recurrence.

2. Variables about renal function change: percent estimated glomerular filtration rate (eGFR) decrease, creatinine increase.

3. Variables about perioperative complications: overall complication rate, intraoperative complication rate, postoperative complication rate.

\section{Data Extraction}

Data from the included studies was extracted and calculated separately by two authors (Deng and Chen). Discussions were necessary until no doubt existed whenever there was a disagreement. Following information was obtained from every included article: first author's family name; year of publication; study design; number of included cases in both groups; cohort representative; surgical approach of each group; comparability between two groups; follow-up outcomes.

\section{Quality assessment and statistical analysis}

Criteria enacted by the Center for Evidence-Based Medicine was used to rate included studies for the level of evidence [27].

The modified Newcastle-Ottawa scale was used to assess the methodological quality of retrospective studies [28]. The scale evaluates risk in three factors of study design: patient selection; comparability between two groups; assessment of outcomes. Every study was scored from 0 to 9 . High quality study was defined as study getting a score of $\geq 7$, otherwise studies were considered to be of moderate quality.

Hazard ratio (HR), mean difference (MD) and the odds ratio (OR) were used to measure the oncological variables, the renal function change and the complication rates, respectively. All outcomes were presented with $95 \%$ confidence intervals (95\%CI). The method summarized by Tierney et al. [29] was used to calculate HRs and 95\% CI when the data wasn't provided directly. When renal function change was presented as medians and ranges, the means provided by Hozo et al. [30] was used to convert the data into means with standard deviations. Yates' correction was used when no complication occurred in one of two groups [31]. 
Chi-squared test with significance set at $p<0.10$ was used to assess the statistical heterogeneity between studies. The $\mathrm{I}^{2}$ statistic was used to quantify heterogeneity. The fixed-effects (FE) model was applied to pool data if no significant heterogeneity existed between studies, or the random-effects model was applied [32].

In order to assess the stability of every outcome of interest, original analyses were repeated with exclusion of the study that got the lowest score to conduct sensitivity analyses. To explore the source of heterogeneity, subgroup analyses were performed according to the quality of included studies.

A funnel plot about all-cause death was inspected visually to assess the potential for publication bias.

Review Manager 5.3 (Cochrane Collaboration, Oxford, UK) was run to conduct all statistical analyses. A p value $<0.05$ was deemed to mean statistically significant.

\section{Results}

\section{Description of Included Studies}

Seventeen studies [2, 3, 8, 10, 13, 14, 16-26] fulfilling the inclusion criteria drafted in advance were singled out from the 1059 potentially relevant studies. Details of study selection were shown in flow-process diagram (Figure 1). All included studies were published in full with a retrospective observational study design. Level of evidence of all selected studies was $3 \mathrm{~b}$ owing to their study design. More characteristics of the included studies were presented in Table 1.

\section{Quality of Eligible Studies}

No appropriate protocol was employed in advance to allocate patients and assign treatment in the retrospective studies, but just according to physician's discretion. Information about allocation concealment or the blinding method was not mentioned in studies. Comparable information about the included patients between the two groups varied from article to article. The mean follow-up period of every group in all studies was up to 6 months. 8 eligible studies got a score $\geq 7$ according to Newcastle-Ottawa Scale (Table S1) $[8,14,16-18,20,24$, 25], while the remaining ones were marked as moderate quality studies $[2,3,10,13,19,21-23,26]$. Most studies did not describe clearly about how to deal with missing data or intention-to-treat analyses.

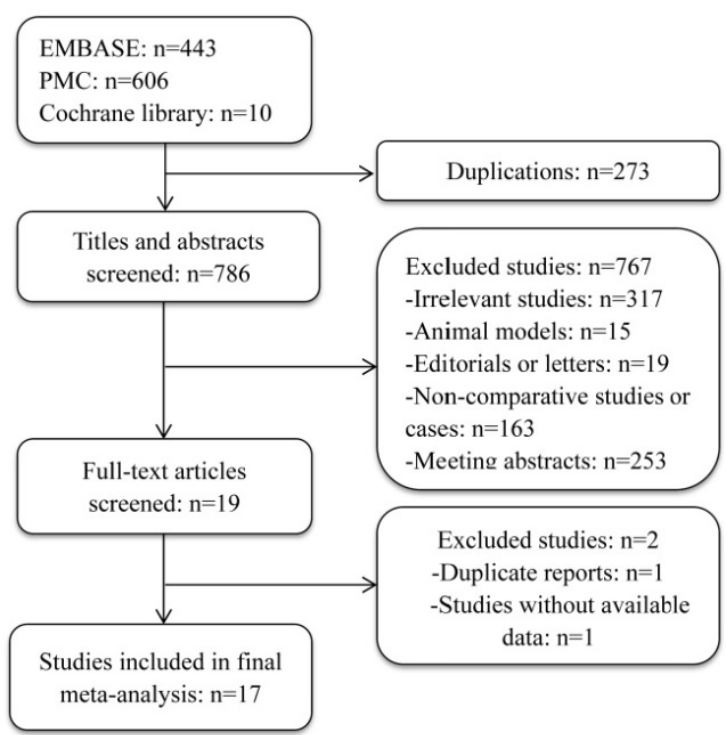

Figure 1. Flowchart of study selection

Table 1. Characteristics of included studies

\begin{tabular}{|c|c|c|c|c|c|c|c|c|c|c|c|}
\hline \multirow[t]{2}{*}{ Study } & \multirow[t]{2}{*}{ Country } & \multirow[t]{2}{*}{ Design } & \multicolumn{2}{|c|}{ Patients, no } & \multicolumn{2}{|c|}{ approach } & \multirow{2}{*}{$\begin{array}{l}\text { Matching } \\
1,2,3,4,5,6,7,8,9,10\end{array}$} & \multicolumn{2}{|c|}{ Follow-up, m } & \multirow{2}{*}{$\begin{array}{l}\text { level of } \\
\text { evidence }\end{array}$} & \multirow{2}{*}{$\begin{array}{l}\text { Quality } \\
\text { Score }\end{array}$} \\
\hline & & & PN & CA & PN & CA & & PN & CA & & \\
\hline Bhindi $^{2018[13]}$ & USA & $\mathrm{R}$ & 64 & 54 & NA & $\mathrm{P}$ & $2,8,10$ & 47 & 47 & $3 b$ & 5 \\
\hline Caputo $2017[14]$ & USA & $\mathrm{R}$ & 31 & 31 & $\mathrm{R}$ & $\mathrm{L}+\mathrm{P}$ & $1,2,3,4,5,8,9,10$ & 13.0 & 30.1 & $3 b$ & 8 \\
\hline Chehab $^{2016}[16]$ & USA & $\mathrm{R}$ & 128 & 37 & $\mathrm{R}+\mathrm{O}$ & $\mathrm{P}$ & $2,3,4,8$ & 28.1 & 22.1 & $3 b$ & 7 \\
\hline Desai $^{2005}[17]$ & USA & $\mathrm{RP}$ & 153 & 78 & $\mathrm{~L}$ & $\mathrm{~L}$ & $2,3,6,7$ & 5.8 & 24.6 & $3 b$ & 7 \\
\hline Emara $^{2014}[2]$ & UK & $\mathrm{R}$ & 47 & 56 & $\mathrm{R}$ & $\mathrm{L}$ & $2,6,8$ & 6 & 6 & $3 b$ & 6 \\
\hline Fraisse $^{2018}[18]$ & France & $\mathrm{R}$ & 470 & 177 & $\mathrm{R}$ & $\mathrm{P}$ & $2,3,4,10$ & 39.03 & 62.59 & $3 b$ & 7 \\
\hline Guillotreau $^{2012}$ [19] & USA & $\mathrm{R}$ & 210 & 226 & $\mathrm{R}$ & $\mathrm{L}$ & $3,6,7$ & 6 & 6 & $3 b$ & 5 \\
\hline Haber $^{2012}[20]$ & USA & $\mathrm{RP}$ & 48 & 30 & $\mathrm{~L}$ & $\mathrm{~L}$ & $1,2,3,4,5,6,7,9,10$ & 42.7 & 60.2 & $3 b$ & 8 \\
\hline Haramis $^{2012}[3]$ & USA & $\mathrm{R}$ & 92 & 75 & $\mathrm{~L}$ & $\mathrm{~L}$ & $2,4,5,6,7,8$ & 21.8 & 14 & $3 b$ & 6 \\
\hline Hruby $^{2006[21]}$ & USA & $\mathrm{R}$ & 12 & 11 & $\mathrm{~L}$ & $\mathrm{~L}$ & 7 & 12 & 11.3 & $3 b$ & 4 \\
\hline Klatte $^{2011[22]}$ & Austria & $\mathrm{R}$ & 82 & 41 & $\mathrm{O}$ & $\mathrm{L}$ & $1,2,4,5,10$ & 33.6 & 33.6 & $3 b$ & 6 \\
\hline $\operatorname{Lin}^{2008}[23]$ & USA & $\mathrm{RP}$ & 14 & 13 & $\mathrm{~L}$ & $\mathrm{~L}$ & $2,3,6,9$ & 38.5 & 24 & $3 b$ & 6 \\
\hline O'Malley' $^{2007}[24]$ & USA & $\mathrm{R}$ & 15 & 15 & $\mathrm{~L}$ & $\mathrm{~L}$ & $1,2,3,4,5,6,7,9$ & 9.83 & 11.9 & $3 b$ & 8 \\
\hline Tanagho $^{2013}[10]$ & USA & $\mathrm{R}$ & 233 & 267 & $\mathrm{R}$ & $\mathrm{L}+\mathrm{P}$ & $2,3,6$ & 21.9 & 39.8 & $3 b$ & 4 \\
\hline Thompson ${ }^{2015}[8]$ & USA & $\mathrm{RP}$ & 1383 & 240 & $\mathrm{O}$ & $\mathrm{P}$ & $1,2,4,5,10$ & 36 & 36 & $3 b$ & 7 \\
\hline Turna $^{2009}[25]$ & USA & $\mathrm{R}$ & 36 & 36 & $\mathrm{~L}$ & $\mathrm{~L}+\mathrm{P}$ & $1,2,3,4,7,9$ & 6 & 6 & $3 b$ & 7 \\
\hline Zondervan ${ }^{2016}[26]$ & Netherland & $\mathrm{R}$ & 124 & 137 & $\mathrm{O}+\mathrm{L}$ & $\mathrm{L}+\mathrm{P}$ & $2,3,10$ & 44 & 43 & $3 b$ & 6 \\
\hline
\end{tabular}




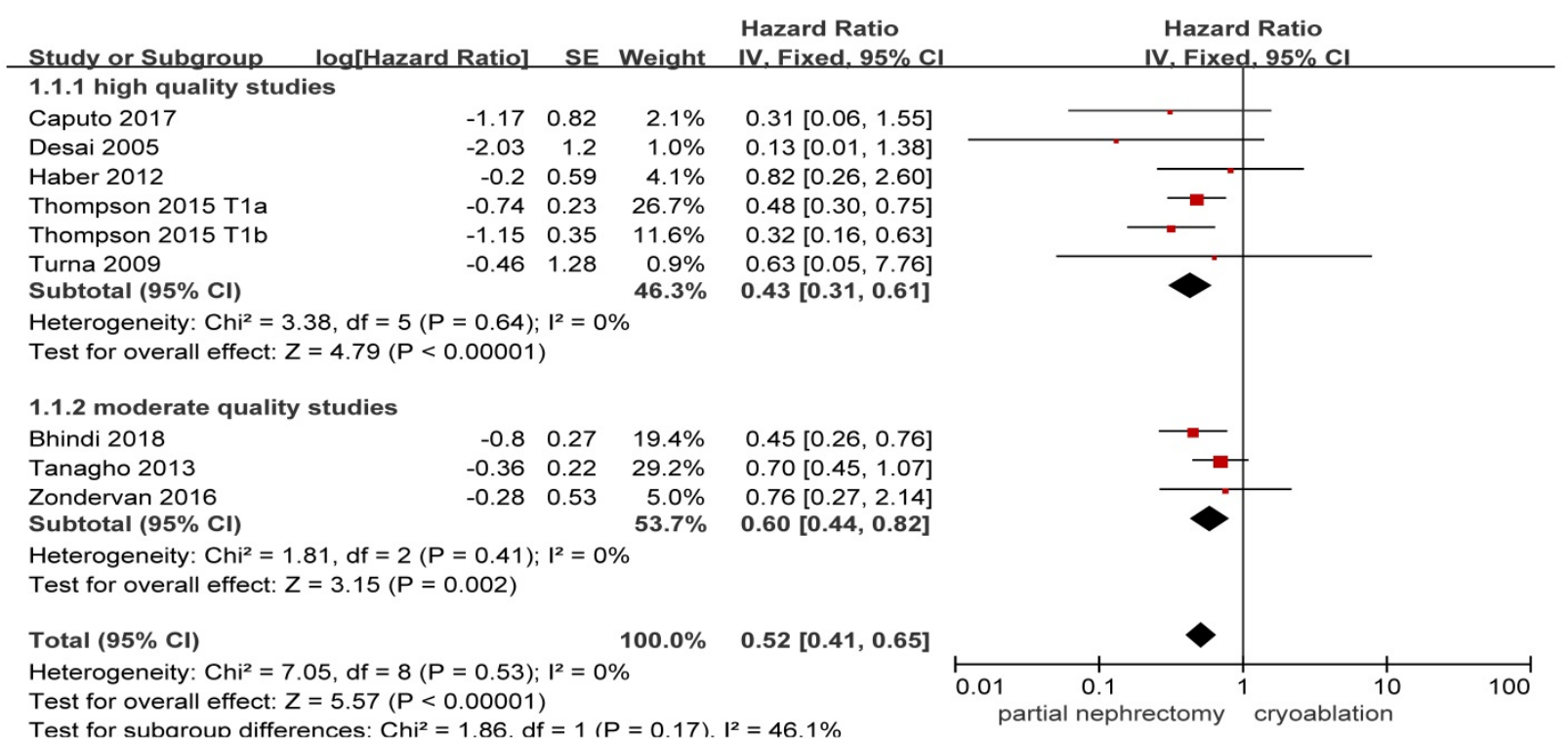

Figure 2. Forest plot and meta-analysis of all-cause death.

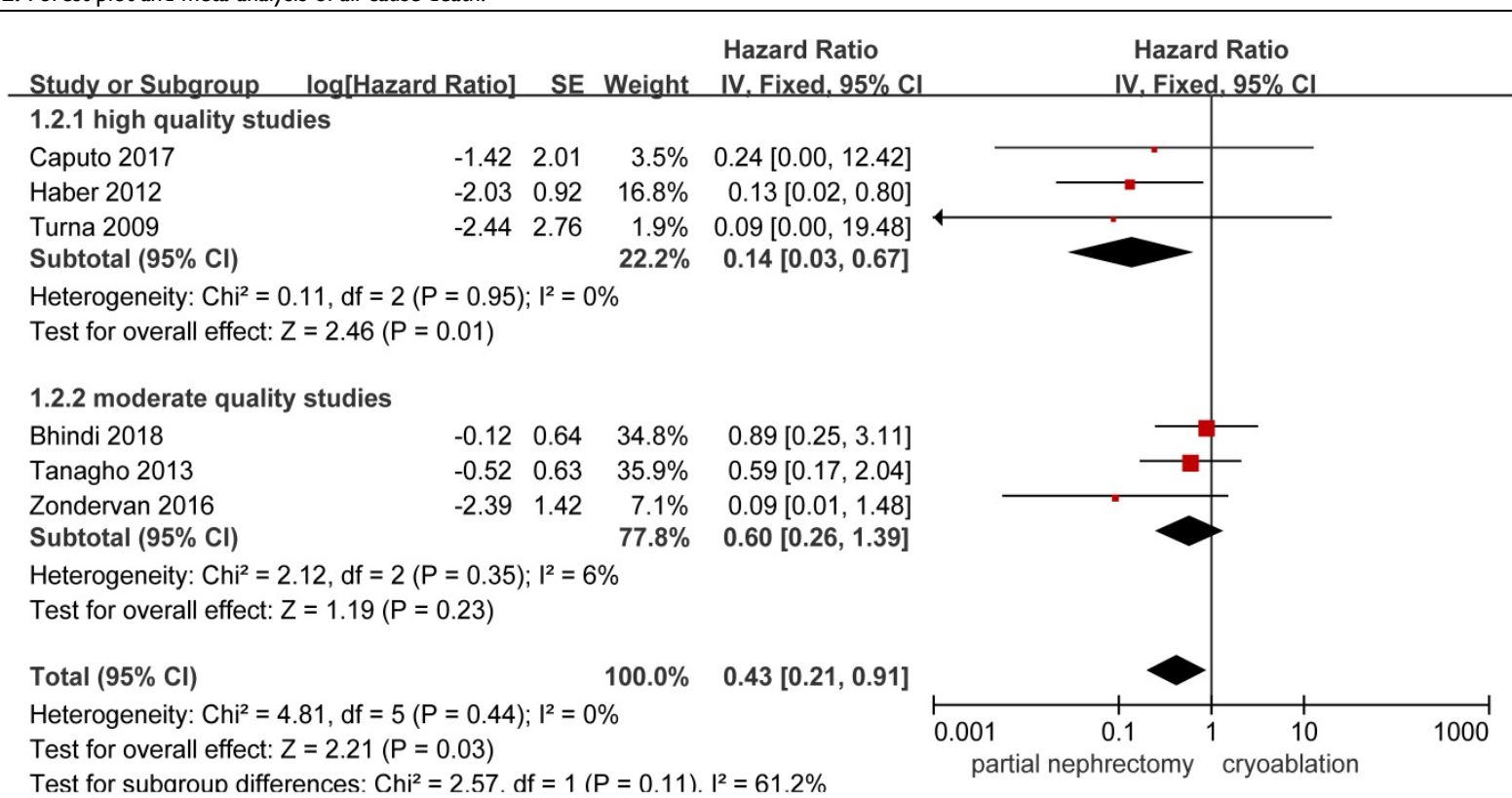

Figure 3. Forest plot and meta-analysis of cancer-specific death.

\section{Oncological Outcomes}

Available data provided by 8 of the 17 studies was pooled for all-cause death with nil heterogeneity $[8,10,13,14,17,20,25,26]$. Original result indicated that stage $\mathrm{T} 1$ patients undergoing $\mathrm{PN}$ showed a significantly lower all-cause death compared with those undergoing cryoablation (HR, 0.52; 95\% CI: 0.41 to $0.65 ; \mathrm{p}<0.001)$. Both the high quality study subgroup and the moderate quality study subgroup got as significant as the original result while the heterogeneity remained nil ((HR, $0.43 ; 95 \% \mathrm{CI}: 0.31$ to $0.61 ; \mathrm{p}<0.001)$ and $(\mathrm{HR}, 0.60 ; 95 \% \mathrm{CI}: 0.44$ to $0.82 ; \mathrm{p}=$ 0.002 ), respectively) (Figure 2).

HRs on cancer-specific death could be extracted or calculated from 6 included studies $[10,13,14,20$,
$25,26]$. Significant higher possibility to cancer-specific death was found in the cryoablation group compared with the PN group (HR, 0.43; 95\%CI: 0.21 to $0.91 ; \mathrm{p}=$ $0.03)$. In the high quality study subgroup, the pooled HR was 0.14 (95\%CI: 0.03 to $0.67 ; p=0.01)$ without between-study heterogeneity. But no significant difference was found between the two treatment groups in the moderate quality study subgroup with slightly increased heterogeneity (HR, 0.60; 95\%CI: 0.26 to $1.39 ; \mathrm{p}=0.23 ; \mathrm{I}^{2}=6 \%$ ) (Figure 3 ).

4 studies [8, 13, 19, 20] including 2255 patients provided available details about the risk of metastasis. Statistical significance in the incidences of metastasis was found between the PN group and the cryoablation group (HR, $0.41 ; 95 \% \mathrm{CI}$ : 0.26 to $0.67 ; \mathrm{p}=$ 
0.0004). The FE model was used to pool the result owing to the low heterogeneity. Results of the two subgroups remained to be significantly different between the two treatment groups, while the heterogeneity between the moderate quality studies increased to a high level (Figure 4).

Data on local-recurrence could be extracted from 11 studies [3, 8, 10, 13, 14, 17-20, 22, 26]. The FE model was used to pool the data on the basis of the insignificant heterogeneity. The rate of local-recurrence in the cryoablation group was significantly higher than that in the PN group (HR, 0.35 ; $95 \%$ CI: 0.25 to $0.50 ; p<0.001)$. Significant results were also concluded in the two subgroups while the heterogeneity between studies was decreased in the high quality subgroup and the opposite change was detected in the moderate quality subgroup (Figure 5).

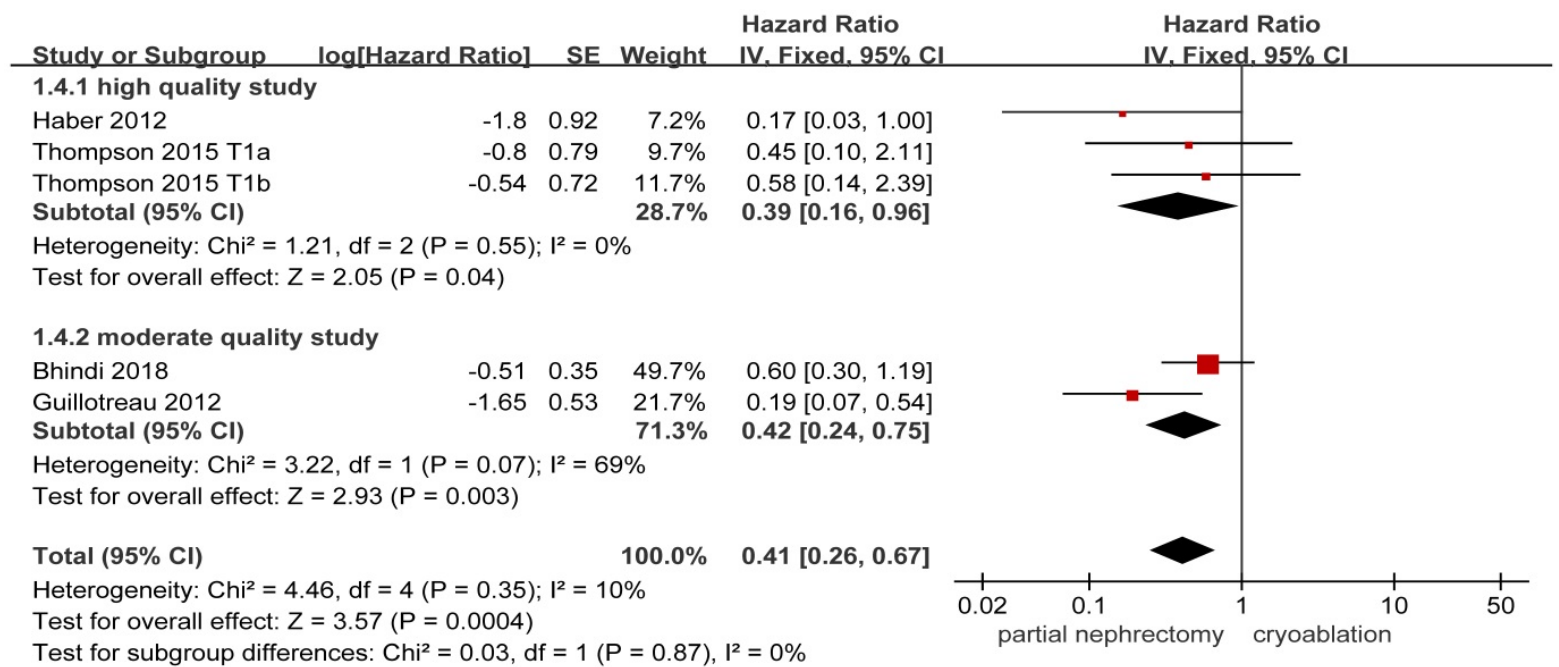

Figure 4. Forest plot and meta-analysis of metastasis.

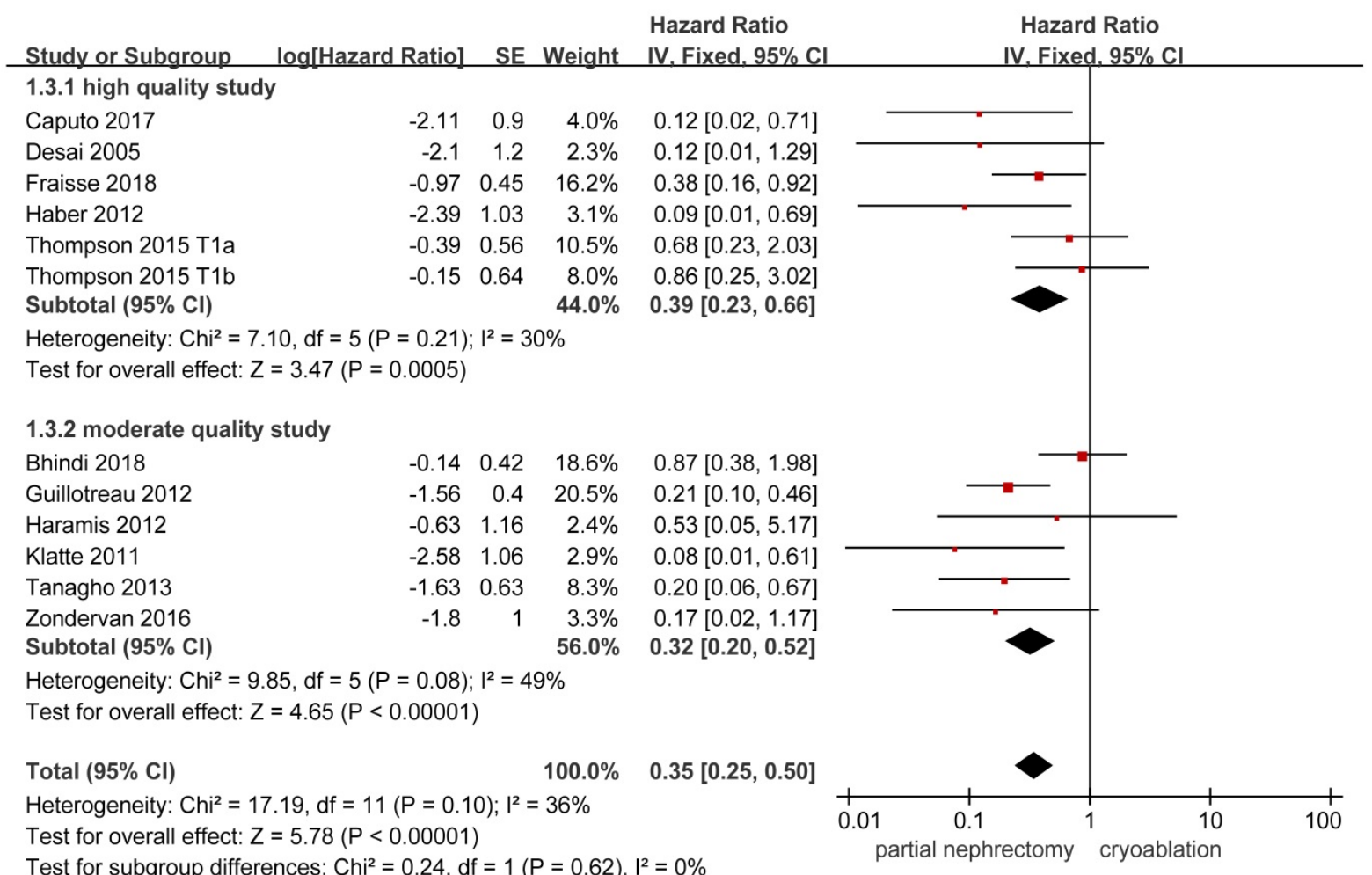

Figure 5. Forest plot and meta-analysis of local-recurrence. 


\section{Renal Function Outcomes}

Pooled data about percent eGFR decrease from 6 studies $[10,13,14,19,20,23]$ indicated a significantly better renal function preservation in the cryoablation group compared with the PN group (MD: -4.84; $95 \%$ CI: -7.02 to $-2.36 ; p<0.0001)$. The data was pooled without heterogeneity using the FE model. Results of the two subgroups were consistent with the original result (Figure 6).

There was no heterogeneity in 3 included studies $[2,20,25]$ focusing on creatinine increase. The pooled WD for creatinine increase was 0.15 (95\%CI: 0.04 to $0.26 ; p=0.006$ ) indicating that cryoablation protected renal function significantly better than $\mathrm{PN}$ for $\mathrm{T} 1$ renal tumor cases. Subgroup analysis showed the same outcome as the original meta-analysis (Figure 7).

\section{Complications Outcomes}

There were significantly more overall complications and postoperative complications in the PN group than the cryoablation group ((OR: 1.86; $95 \% \mathrm{CI}: 1.28$ to $2.70 ; \mathrm{p}=0.001)$ and (OR: $2.97 ; 95 \% \mathrm{CI}$ : 2.13 to $4.14 ; \mathrm{p}<0.001$ ), respectively) (Figures 8 and 9). But no significant difference was found in intraoperative complication rate between two groups (OR: 2.02; 95\%CI: 0.22 to 18.51; p = 0.53) (Figure 10). For three complication variables, pooled data of all subgroups were in accordance with those original results.

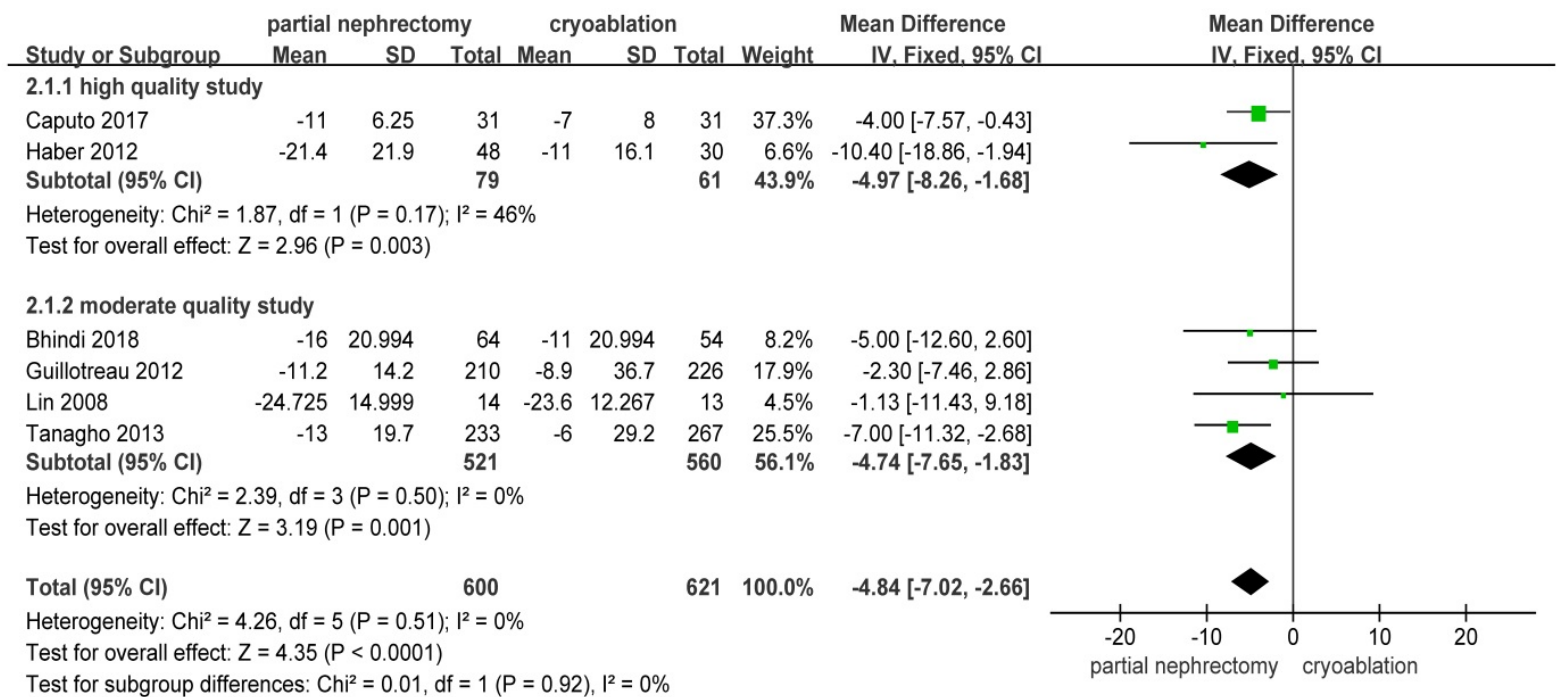

Figure 6. Forest plot and meta-analysis of percent eGFR decrease.

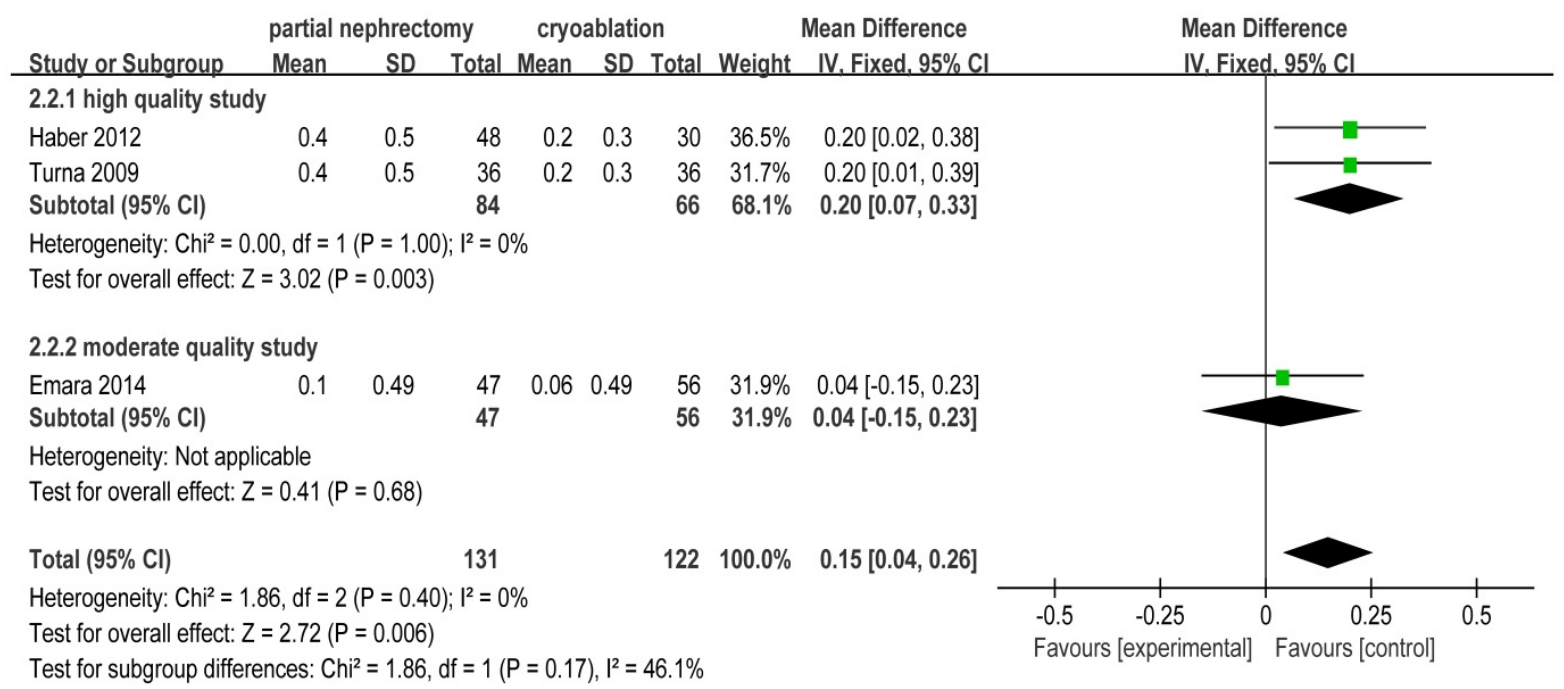

Figure 7. Forest plot and meta-analysis of creatinine increase. 


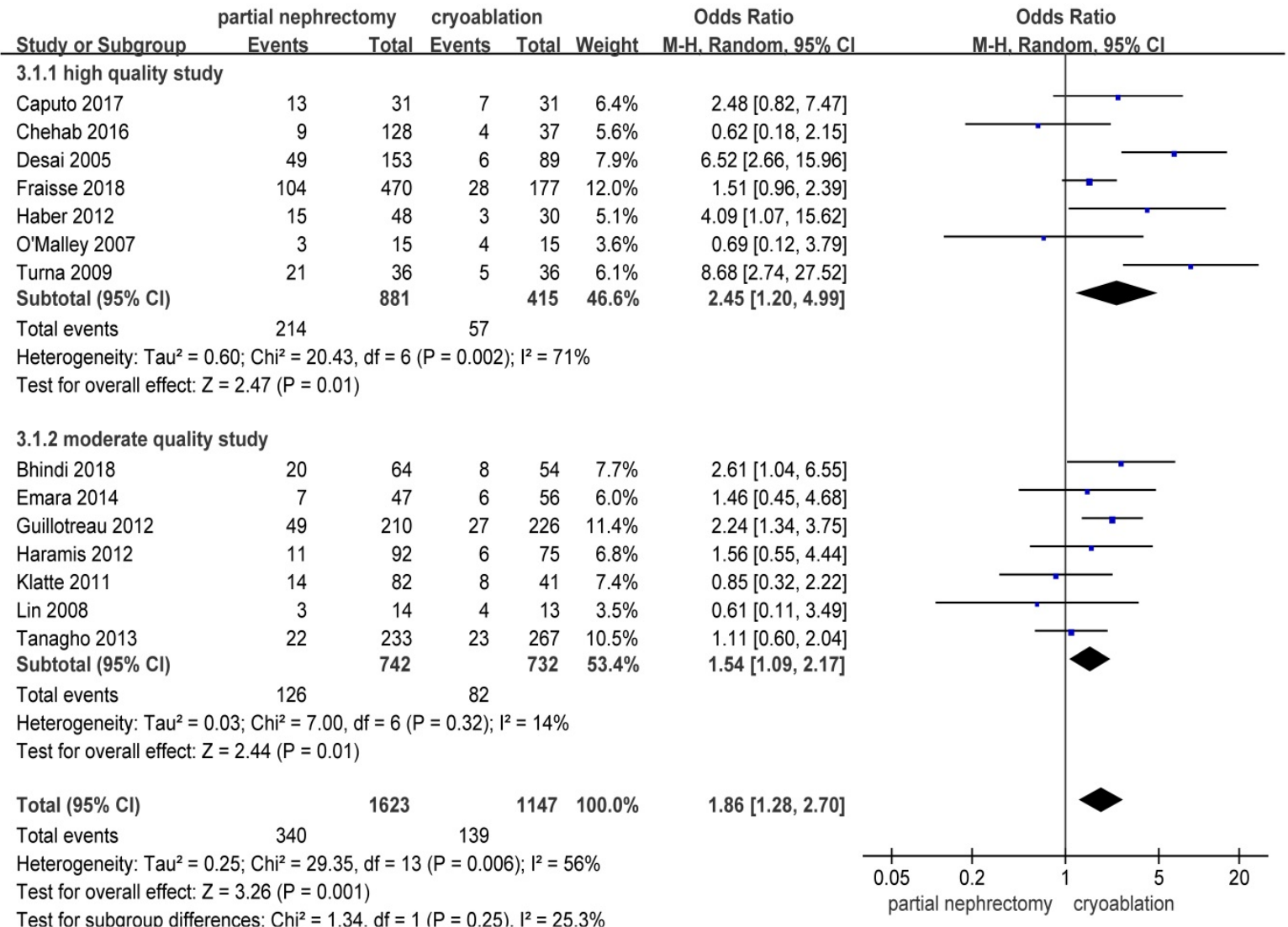

Figure 8. Forest plot and meta-analysis of overall complication rates.

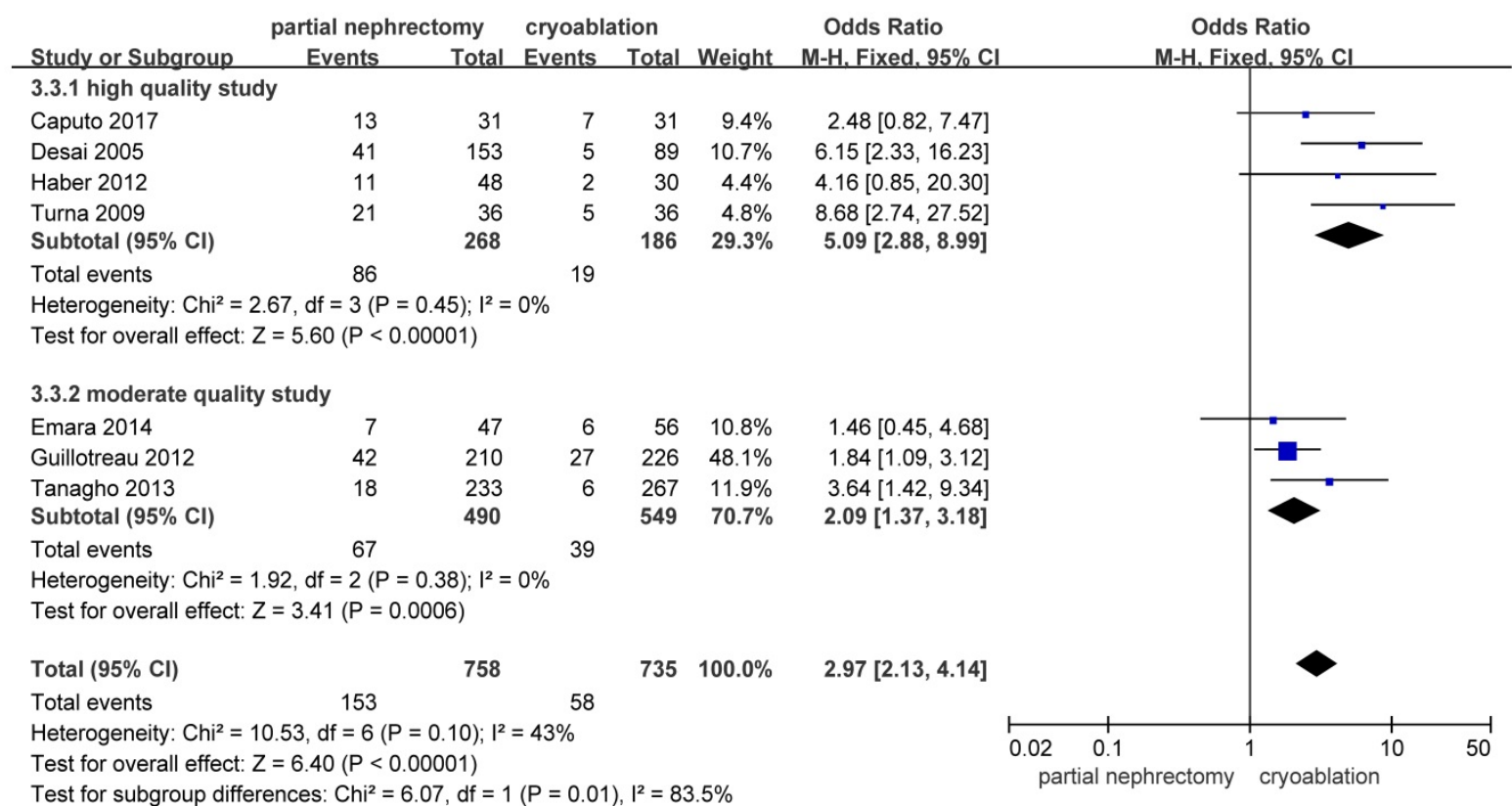

Figure 9. Forest plot and meta-analysis of postoperative complication rates. 


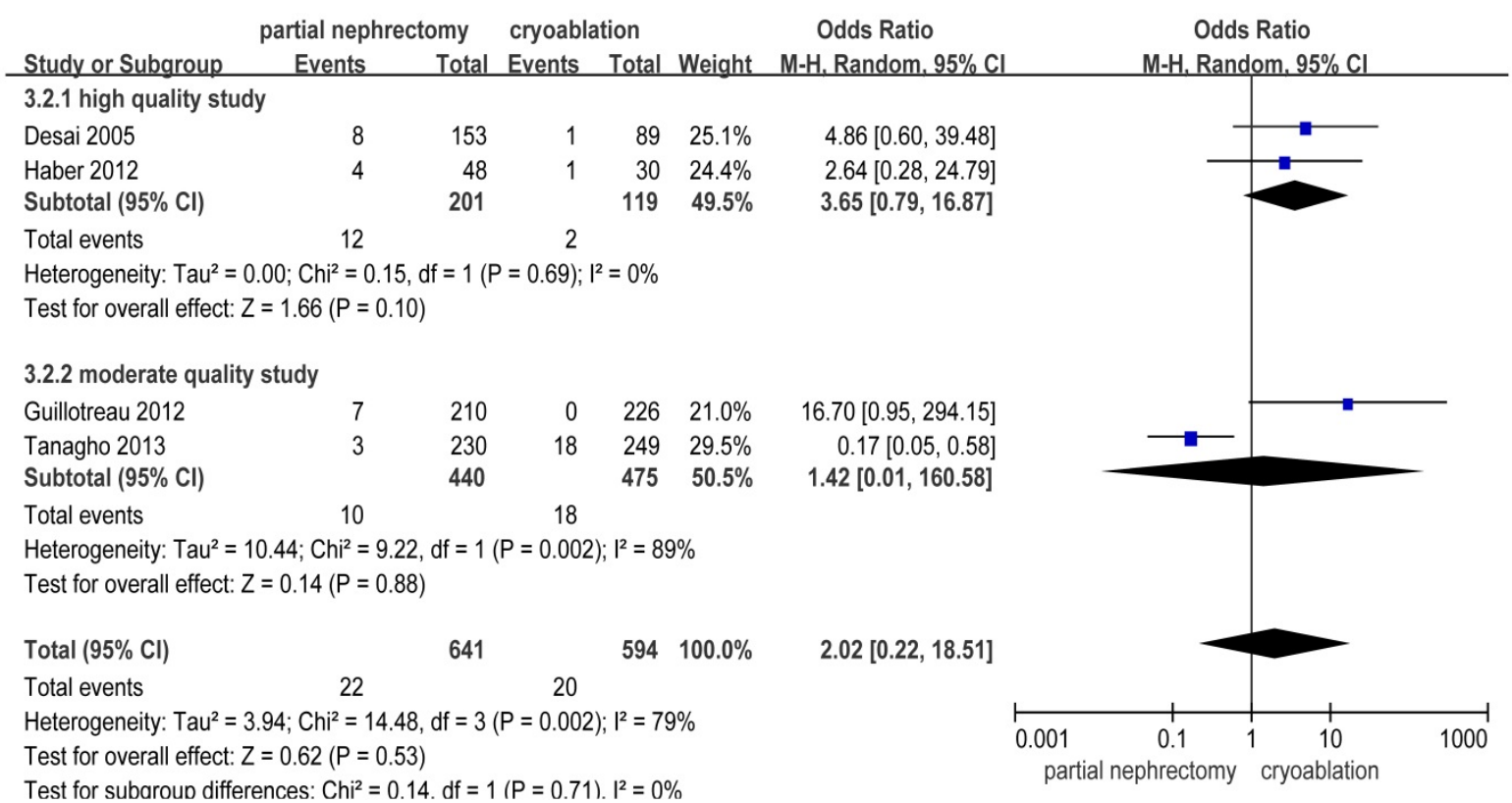

Figure 10. Forest plot and meta-analysis of intraoperative complication rates.

Table 2. Results of meta-analysis and sensitivity analysis about comparison of partial nephrectomy and cryoablation

\begin{tabular}{|c|c|c|c|c|c|c|c|c|c|}
\hline \multirow[t]{2}{*}{ Outcomes of interest } & \multirow[t]{2}{*}{ Studies, no } & \multirow[t]{2}{*}{ PN patient, no } & \multirow[t]{2}{*}{ cryoablation patients, no } & \multirow[t]{2}{*}{ HR/WMD/OR (95\%CI) } & \multirow[t]{2}{*}{$p$ value } & \multicolumn{4}{|c|}{ Study heterogeneity } \\
\hline & & & & & & $\mathrm{Chi}^{2}$ & df & $p$ & $I^{2}, \%$ \\
\hline \multicolumn{10}{|l|}{ Oncologic outcomes } \\
\hline All-cause death & 8 & 2072 & 873 & $0.52(0.41,0.65)^{r}$ & $<0.001$ & 7.05 & 8 & 0.53 & 0 \\
\hline Exclusion of [10] & 7 & 1839 & 606 & $0.46(0.35,0.60)^{r}$ & $<0.001$ & 4.38 & 7 & 0.73 & 0 \\
\hline Cancer-specific death & 6 & 536 & 555 & $0.43(0.21,0.91)^{r}$ & 0.03 & 4.81 & 5 & 0.44 & 0 \\
\hline Exclusion of [10] & 5 & 303 & 288 & $0.36(0.14,0.92)^{r}$ & 0.03 & 4.42 & 4 & 0.35 & 9 \\
\hline Metastasis & 4 & 1705 & 550 & $0.41(0.26,0.67)^{r}$ & 0.0004 & 4.46 & 4 & 0.35 & 10 \\
\hline Exclusion of [13] & 3 & 1641 & 496 & $0.29(0.15,0.57)^{r}$ & 0.0003 & 2.22 & 3 & 0.53 & 0 \\
\hline Local-recurrence & 11 & 2597 & 1356 & $0.35(0.25,0.50)^{r}$ & $<0.001$ & 17.19 & 11 & 0.10 & 36 \\
\hline Exclusion of [10] & 10 & 2364 & 1089 & $0.34(0.20,0.57)^{\vdash}$ & $<0.001$ & 16.25 & 10 & 0.09 & 38 \\
\hline \multicolumn{10}{|l|}{ Renal function outcomes } \\
\hline Percent eGFR decrease & 6 & 600 & 621 & $-4.84(-7.02,-2.66)$ & $<0.001$ & 4.26 & 5 & 0.51 & 0 \\
\hline Exclusion of [10] & 5 & 367 & 354 & $-4.10(-6.63,-1.57)$ & 0.001 & 2.98 & 4 & 0.56 & 0 \\
\hline Creatinine increase & 3 & 131 & 122 & $0.15(0.04,0.26)$ & 0.006 & 1.86 & 2 & 0.40 & 0 \\
\hline Exclusion of [2] & 2 & 84 & 66 & $0.20(0.07,0.33)$ & 0.003 & 0.00 & 1 & 1.00 & 0 \\
\hline \multicolumn{10}{|l|}{ Complications } \\
\hline Overall complications & 14 & 1623 & 1147 & $1.86(1.28,2.70)^{+}$ & 0.001 & 29.35 & 13 & 0.006 & 56 \\
\hline Exclusion of [10] & 13 & 1390 & 880 & $1.97(1.33,2.94)^{+}$ & 0.008 & 26.41 & 12 & 0.009 & 55 \\
\hline Intraoperative complications & 4 & 641 & 594 & $2.02(0.22,18.51)^{+}$ & 0.53 & 14.48 & 3 & 0.002 & 79 \\
\hline Exclusion of [10] & 3 & 411 & 345 & $5.93(1.59,22.07)^{+}$ & 0.008 & 1.04 & 2 & 0.60 & 0 \\
\hline Postoperative complications & 7 & 758 & 735 & $2.97(2.13,4.14)^{+}$ & $<0.001$ & 10.53 & 6 & 0.10 & 43 \\
\hline Exclusion of [10] & 6 & 525 & 468 & $3.15(1.75,5.69)^{+}$ & 0.0001 & 10.22 & 5 & 0.07 & 51 \\
\hline
\end{tabular}

$\mathrm{PN}=$ partial nephrectomy; HR/WMD/OR = hazard ratio/weighted mean difference $/$ odds ratio; $\mathrm{CI}=$ confidence interval; $\mathrm{df}=\mathrm{degrees}$ of freedom; $\mathrm{eGFR}=\mathrm{estimated}$ glomerular filtration rate;

hazard ratio; ${ }^{+}$Odds ratio.

\section{Sensitivity Analysis}

Sensitivity analyses were conducted by exclusion of the lowest scored study among included studies. All results except for the intraoperative complication rate were accordant with the primary outcomes. As to intraoperative complications, significant difference between the PN group and the cryoablation group was found after removing the study reported by Tanagho et al. [10] and the heterogeneity between studies decreased to nil (OR: 5.93; 95\% CI: 1.59 to 22.07; $\mathrm{p}=0.008 ; \mathrm{I}^{2}=0 \%$ ) (Table 2).

\section{Publication Bias}

A funnel plot of included studies reporting all-cause death was showed as Figure 11. All studies were located inside the $95 \% \mathrm{CI}$, which meant there was no obvious publication bias. 


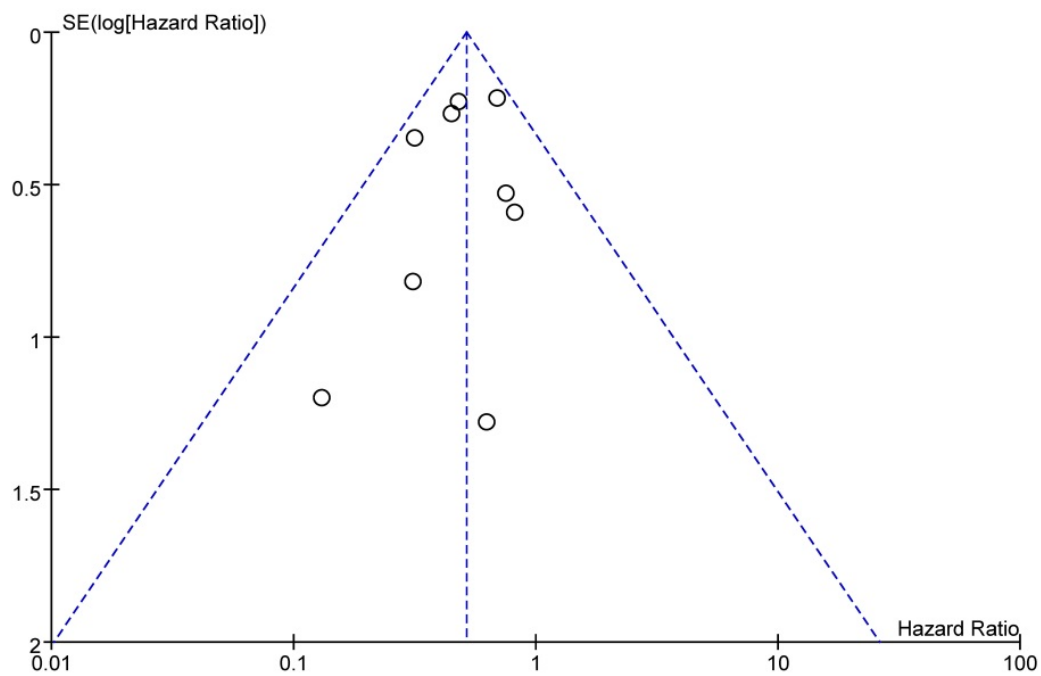

Figure 11. Funnel plot of the studies that reported all-cause death

\section{Discussion}

PN has been recommended as management for T1 renal tumors in guideline [4]. For elderly patients or those with medical comorbidities, a higher surgical risk is accompanied with PN. Cryoablation has been regarded as an alternative to $\mathrm{PN}$ for T1 renal masses $[8,14]$. However, whether cryoablation could lead to low levels of morbidities and surgical complications compared with those found in patients undergoing PN remained controversial and need to be proved further.

We report the first meta-analysis of studies comparing cryoablation to $\mathrm{PN}$ for clinical $\mathrm{T} 1$ renal masses, for which the role of cryoablation is still debated [10, 13, 14]. 17 eligible studies including a total number of 4666 patients can contribute to the ongoing discuss, providing a method for further research on this topic. Cryoablation for stage T1 renal tumors is a better choice to preserve nephron with less technically demand compared with PN. But the existing advantages are counterbalanced by the worse efficacy of cryoablation to $\mathrm{PN}$ in achieving effective oncological outcomes.

With regard to applying any new procedure, the safety is of primary significance to be taken into consideration. Both PN and cryoablation have been widely proved to be safe in the management of T1 renal masses [19]. PN which usually requires time-sensitive suturing with hilus clamping is more technically challenging than cryoablation [20]. According to our results a higher risk of incidences of both overall and postoperative complications was conveyed in PN group. Though no statistically significant difference about intraoperative complications between the two groups was found in original meta-analysis which was pooled with high heterogeneity, the result turned to significant in sensitivity analysis pooled without heterogeneity by eliminating the study reported by Tanagho et al. [10], in which many baseline characteristics were not comparable between two groups. The sensitivity analysis for intraoperative complications may hint the lower risk during the cryoablation procedure, which need to be proved further with more homogeneous studies.

Better oncological control is always pursued in management of tumors. PN achieved a better prognosis compared with cryoablation with respect to all variables including all-cause death, cancer-specific death, metastasis and local-recurrence. All results were pooled with nil or low heterogeneity. Selected patients who were considered more suitable to cryoablation were usually at elder age or with significant comorbidities $[10,13,17,19,20,26]$. The selection bias contributed to the significant difference about oncological outcomes between two treatments. 4 of 11 studies providing information about oncological outcomes were at risk of a significant bias on tumor size $[10,17,19,26]$, but these results may be strengthened by the poorer prognostic feature that all mean tumor diameters in the PN group among these studies were significantly bigger. When matching these three factors, pooled results about all-cause death and cancer-specific death in the high quality study subgroup kept significantly different between the two treatments ((I2: $0 \%$; HR: $0.43 ; 95 \% \mathrm{CI}: 0.31$ to $0.61 ; p<0.001)$ and (I2: 0\%; HR: $0.14 ; 95 \%$ CI: 0.03 to $0.67 ; \mathrm{p}=0.01)$, respectively), which implies that cryoablation brings poorer rates of overall survival and cancer-specific survival. Similar results about local-recurrence and metastasis have been summarized in study comparing laparoscopic cryoablation and laparoscopic PN reported by Tang et al. [15]. Rate of local-recurrence and metastases after 
renal cryoablation was deemed to be higher with more extended follow-up period [11]. Ultrasound was used to show the advancing edge of the ice ball without providing information on whether the lethal temperature has been achieved during cryoablation through laparoscopic or percutaneous approach [33], which may be the reason of poorer oncological outcomes after cryoablation.

To accomplish preservation of renal function was one of the main targets of nephron-sparing surgery $[19,34]$. It is no doubt that $\mathrm{PN}$ and cryoablation are both effective in renal function protection [11, 35]. Cryoablation was associated with significantly less percent eGFR decrease and creatinine increase compared with $\mathrm{PN}$. PN was usually conducted with hilum clamping, which was significantly associated with worse renal function [36]. Renal ischemia and actual parenchymal resection represent two separate mechanisms for potential renal function decrease during PN [37]. Cryoablation allows for direct visualization with laparoscopic approach or for real-time monitoring with percutaneous approach [13], which preserve functional nephron potentially [20,33, 38].

Several limitations are worthy of discussion. The primary limitation of this systematic review and meta-analysis was that no randomized controlled trials were included, which made it hard to acquire enough data for meaningful results. Second, surgeries were performed by surgeons with different levels of surgical expertise and different choices of surgical approaches. Thirdly, patient allocation and treatment assignment were usually up to physician's attitude instead of randomized allocation, which led to a significant selection bias. Cryoablation was usually applied in elderly patient with significant comorbidities or those with a shorter life expectancy. Partial nephrectomy was chosen for renal masses with larger size. Next to last, the limited mean follow-ups in some studies resulted in follow-up bias. Finally, data about the incidences of complications was pooled with moderate or high heterogeneity using FE model.

Notable strengths of this systematic review are as follows. This is the first systematic review and meta-analysis comparing between cryoablation and PN for clinical T1 renal masses. The meta-analysis was conducted at an appropriate time, because more and more incidental renal tumors have been detected and enough studies have accumulated for inspection by meta-analytical methods. Studies were identified using multiple strategies, the methodological quality of the studies were evaluated according to strict inclusion and exclusion. Subgroup and sensitivity analysis were used to analyze the source of heterogeneity. Publication bias was not obvious with direct intuition.

\section{Conclusions}

Comparing with PN, cryoablation for clinical T1 renal tumors is associated with poorer oncological outcomes, but the existing disadvantages are accompanied by lower rate of overall and postoperative complications and superior renal functional preservation. For patients with imperative indications for nephron-sparing surgery who can't risk more invasive $\mathrm{PN}$, cryoablation could be an attractive option. Owing to the inherent limitations of eligible studies, conclusions drawn from our meta-analyses should be interpreted cautiously and be confirmed further with well-designed randomized controlled trials with extensive follow-up length.

\section{Abbreviations}

PN: partial nephrectomy; eGFR: estimated glomerular filtration rate; HR: Hazard ratio; MD: mean difference; OR: odds ratio; $\mathrm{CI}$ : confidence interval; FE: fixed-effects.

\section{Supplementary Material}

Supplementary table.

http://www.jcancer.org/v10p1226s1.pdf

\section{Competing Interests}

The authors have declared that no competing interest exists.

\section{References}

1. Rossi SH, Klatte T. Epidemiology and screening for renal cancer. World journal of urology. 2018; 36: 1341-53.

2. Emara AM, Kommu SS, Hindley RG, Barber NJ. Robot-assisted partial nephrectomy vs laparoscopic cryoablation for the small renal mass: redefining the minimally invasive 'gold standard'. BJU international. 2014; 113: 92-9.

3. Haramis G, Graversen JA, Mues AC, Korets R, Rosales JC, Okhunov Z, et al. Retrospective comparison of laparoscopic partial nephrectomy versus laparoscopic renal cryoablation for small $(<3.5 \mathrm{~cm})$ cortical renal masses. Journal of laparoendoscopic \& advanced surgical techniques Part A. 2012; 22: $152-7$

4. Ljungberg B, Bensalah K, Canfield S, Dabestani S, Hofmann F, Hora M, et al. EAU guidelines on renal cell carcinoma: 2014 update. European urology. 2015; 67: 913-24

5. Van Poppel H, Becker F, Cadeddu JA, Gill IS, Janetschek G, Jewett MA, et al. Treatment of localised renal cell carcinoma. European urology. 2011; 60: 662-72.

6. Ng AM, Shah PH, Kavoussi LR. Laparoscopic Partial Nephrectomy: A Narrative Review and Comparison with Open and Robotic Partial Nephrectomy. Journal of endourology. 2017; 31: 976-84

7. Bhindi B, Thompson RH, Mason RJ, Haddad MM, Geske JR, Kurup AN, et al. Comprehensive assessment of renal tumour complexity in a large percutaneous cryoablation cohort. BJU international. 2017; 119: 905-12.

8. Thompson RH, Atwell T, Schmit G, Lohse CM, Kurup AN, Weisbrod A, et al. Comparison of partial nephrectomy and percutaneous ablation for CT1 renal masses. European urology. 2015; 67: 252-9.

9. El Dib R, Touma NJ, Kapoor A. Cryoablation vs radiofrequency ablation for the treatment of renal cell carcinoma: a meta-analysis of case series studies. BJU international. 2012; 110: 510-6.

10. Tanagho YS, Bhayani SB, Kim EH, Figenshau RS. Renal cryoablation versus robot-assisted partial nephrectomy: Washington University long-term experience. Journal of endourology. 2013; 27: 1477-86.

11. Klatte T, Grubmuller B, Waldert M, Weibl P, Remzi M. Laparoscopic cryoablation versus partial nephrectomy for the treatment of small renal 
masses: systematic review and cumulative analysis of observational studies. European urology. 2011; 60: 435-43.

12. Tsivian M, Chen VH, Kim CY, Zilberman DE, Mouraviev V, Nelson RC, et al. Complications of laparoscopic and percutaneous renal cryoablation in a single tertiary referral center. European urology. 2010; 58: 142-7.

13. Bhindi B, Mason RJ, Haddad MM, Boorjian SA, Leibovich BC, Atwell TD, et al. Outcomes After Cryoablation Versus Partial Nephrectomy for Sporadic Renal Tumors in a Solitary Kidney: A Propensity Score Analysis. European urology. 2018; 73: 254-9.

14. Caputo PA, Zargar H, Ramirez D, Andrade HS, Akca O, Gao T, et al. Cryoablation versus Partial Nephrectomy for Clinical T1b Renal Tumors: A Matched Group Comparative Analysis. European urology. 2017; 71: 111-7.

15. Tang K, Yao W, Li H, Guo X, Guan W, Ma X, et al. Laparoscopic renal cryoablation versus laparoscopic partial nephrectomy for the treatment of small renal masses: a systematic review and meta-analysis of comparative studies. Journal of laparoendoscopic \& advanced surgical techniques Part A. 2014; 24: 403-10

16. Chehab M, Friedlander JA, Handel J, Vartanian S, Krishnan A, Wong CY, et al. Percutaneous Cryoablation vs Partial Nephrectomy: Cost Comparison of T1a Tumors. Journal of endourology. 2016; 30: 170-6.

17. Desai MM, Aron M, Gill IS. Laparoscopic partial nephrectomy versus laparoscopic cryoablation for the small renal tumor. Urology. 2005; 66: 23-8.

18. Fraisse G, Colleter L, Peyronnet B, Khene Z, Mandoorah Q, Soorojebally Y, et al. Perioperative and local control outcomes of robot-assisted partial nephrectomy vs percutaneous cryoablation for renal masses: Comparison after matching on radiological stage and renal score. BJU international. 2018; [Epub ahead of print].

19. Guillotreau J, Haber GP, Autorino R, Miocinovic R, Hillyer S, Hernandez A, et al. Robotic partial nephrectomy versus laparoscopic cryoablation for the small renal mass. European urology. 2012; 61: 899-904.

20. Haber GP, Lee MC, Crouzet S, Kamoi K, Gill IS. Tumour in solitary kidney: laparoscopic partial nephrectomy vs laparoscopic cryoablation. BJU international. 2012; 109: 118-24.

21. Hruby G, Reisiger K, Venkatesh R, Yan Y, Landman J. Comparison of laparoscopic partial nephrectomy and laparoscopic cryoablation for renal hilar tumors. Urology. 2006; 67: 50-4.

22. Klatte T, Mauermann J, Heinz-Peer G, Waldert M, Weibl P, Klingler HC, et al. Perioperative, oncologic, and functional outcomes of laparoscopic renal cryoablation and open partial nephrectomy: a matched pair analysis. Journal of endourology. 2011; 25: 991-7.

23. Lin YC, Turna B, Frota R, Aron M, Haber GP, Kamoi K, et al. Laparoscopic partial nephrectomy versus laparoscopic cryoablation for multiple ipsilateral renal tumors. European urology. 2008; 53: 1210-6.

24. O'Malley RL, Berger AD, Kanofsky JA, Phillips CK, Stifelman M, Taneja SS. A matched-cohort comparison of laparoscopic cryoablation and laparoscopic partial nephrectomy for treating renal masses. BJU international. 2007; 99: 395-8.

25. Turna B, Kaouk JH, Frota R, Stein RJ, Kamoi K, Gill IS, et al. Minimally invasive nephron sparing management for renal tumors in solitary kidneys. The Journal of urology. 2009; 182: 2150-7.

26. Zondervan PJ, van Lienden KP, van Delden OM, de la Rosette JJ, Laguna MP. Preoperative Decision Making for Nephron-Sparing Procedure in the Renal Mass: Time for Using Standard Tools? Journal of endourology. 2016; 30: 128-34.

27. [Internet] Phillips B, Ball C, Sackett D, Badenoch D, Straus S. Levels of Evidence and Grades of Recommendation. Accessed April 26, 2012. http://www.cebm.net/index.aspx?o=1025.

28. [Internet] Wells G, Shea B, O'Connell D, Peterson J, Welch V, Losos M, et al. The Newcastle-Ottawa Scale (NOS) for assessing the quality of nonrandomised studies in meta-analyses. Accessed July 4. 2017. http://www.ohri.ca/programs/clinical_epidemiology/oxford.htm.

29. Tierney JF, Stewart LA, Ghersi D, Burdett S, Sydes MR. Practical methods for incorporating summary time-to-event data into meta-analysis. Trials. 2007; 8: 16.

30. Hozo SP, Djulbegovic B, Hozo I. Estimating the mean and variance from the median, range, and the size of a sample. BMC Medical Research Methodology. 2005; 5 : 13 .

31. Mantel N, Haenszel W. Statistical aspects of the analysis of data from retrospective studies of disease. Journal of the National Cancer Institute. 1959; 22: $719-48$.

32. [Internet] The Cochrane Collaboration, 2011. Cochrane Handbook for Systematic Reviews of Interventions Version 5.1.0 [updated March 2011]. http://handbook.cochrane.org. 2011.

33. Ismail M, Nielsen TK, Lagerveld B, Garnon J, Breen D, King A, et al. Renal cryoablation: Multidisciplinary, collaborative and perspective approach. Cryobiology. 2018; 83: 90-4

34. Volpe A, Cadeddu JA, Cestari A, Gill IS, Jewett MA, Joniau S, et al. Contemporary management of small renal masses. European urology. 2011; 60: 501-15.

35. Mason RJ, Atwell TD, Lohse C, Bhindi B, Weisbrod A, Boorjian SA, et al. Renal functional outcomes in patients undergoing percutaneous cryoablation or partial nephrectomy for a solitary renal mass. BJU international. 2017; 120: $544-9$
36. Deng W, Liu X, Hu J, Chen L, Fu B. Off-clamp partial nephrectomy has a positive impact on short- and long-term renal function: a systematic review and meta-analysis. BMC Nephrology. 2018; 19: 188.

37. Schiffman M, Moshfegh A, Talenfeld A, Del Pizzo JJ. Laparoscopic renal cryoablation. Seminars in interventional radiology. 2014; 31: 64-9.

38. Azevedo AAP, Rahal AJ, Falsarella PM, Lemos GC, Claros OR, Carneiro A, et al. Image-guided percutaneous renal cryoablation: Five years experience, results and follow-up. European journal of radiology. 2018; 100: 14-22. 